Faculdade de Ciências Econômicas UFRGS
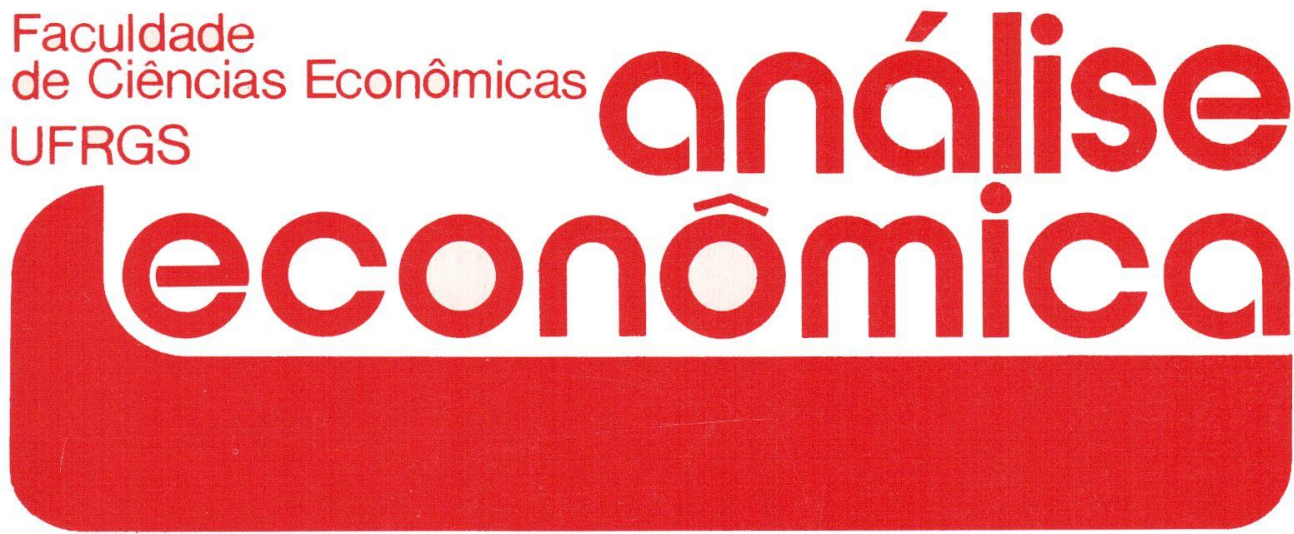

- INDEXAÇĀo SALARIAL: UMA ABORDAGEM MACROECONÓMICA Jo Anna Grav

- AJUSTE NO EMPREGO E PRODUTIVIDADE NA DECADA DE OITENTA

Carlos Antônio Luque José Paulo Zeeteno Chahad

- O CONSUMIDOR KEYNESIANO Marcelo Córtes Neri

- HETEROGENEIDADE DO TRABALHO E TAXA DE LUCRO EM MARX

Francisco Cribari Neto

- ECONOMIAS DE ESCALA: UMA REVISĀO Jesiel de Marco Gomes

- Concentraçấo bancária no BRASIL

Marcelo Resende

- NOYOS RUMOS PARA O SETOR ELETRICO NO BRASIL

Adriano Pires Rodrigues

Eduardo da Cunha Vianna

- OFERTA E DEMANDA DE FRANGO DE CORTE NO BRASIL

Narciso Gonçalves de Castro et alii

- ANÁLISE ECONÔMICA DA IRRIGAÇÃo DO MILHO

Lúcia M Schirmer

Juvir Luiz Mattuella

- REFLORESTAMENTO NO BRASIL. Carlos José Caetano Bacha

- ESCOLHA DE TECNOLOGIA EM ESTRUTURA DE PRINCIPAL AGENTE Kyle D. Kauffma:

- A QUESTÁo DEMOGRÁfica e A PRAXEOLOGIA

Anton Karl Biedermann et alii
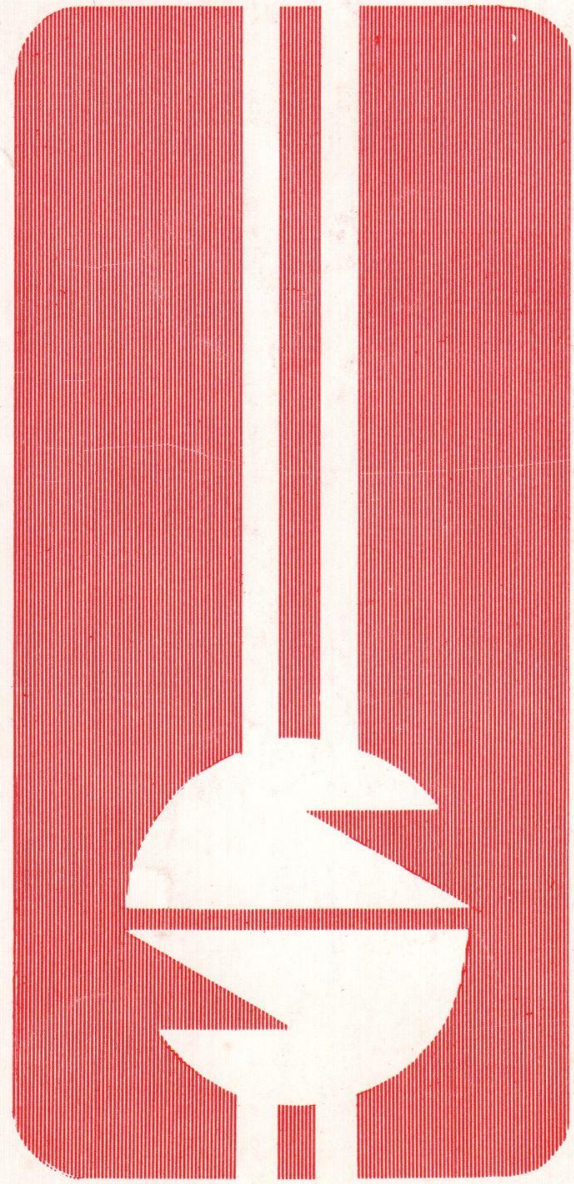
UNIVERSIDADE FEDERAL DO RIO GRANDE DO SUL

Reitor: Prof. Tuiskon Dick

FACULDADE DE CIÉNCIAS ECONÔMICAS

Diretora: Prof ${ }^{\text {a }}$ Yeda Rorato Crusius.

CENTRO DE ESTUDOS E PESQUISAS ECONÔMICAS

Diretor: Reinaldo Ignacio Adams

DEPARTAMENTO DE CIÉNCIAS ECONÔMICAS

Chefe: Prof. Fernando Ferrari Filho

CURSO DE POS-GRADUAÇÄO EM ECONOMIA

Coordenador: Prof. Nali de Jesus de Souza

CURSO DE PÓS-GRADUAÇĀO EM ECONOMIA RURAL

Coordenador: Prof. Atos Freitas Grawunder

CONSELHO EDITORIAL: Achyles Barcelos da Costa, Aray Miguel Feldens, Atos Freitas Grawunder, Carlos Augusto Crusius, Ernani Hickmann, João Rogério Sanson, Juvir Luiz Mattuella, Maria Imilda da Costa e Silva, Nali de Jesus de Souza, Nuno Renan Lopes de Figueiredo Pinto, Otilia Beatriz Kroeff Carrion, Otto Guilherme Konzen, Paulo Alexandre Spohr, Pedro Cezar Dutra Fonseca, Reinaldo Ignacio Adams, Roberto Camps Moraes, Valter José Stülp, Yeda Rorato Crusius, David Garlow (Wharton Econometrics Forecasts Association, E.U.A.), Edgar Augusto Lanzer (UFSC), Eleutério F.S. Prado (USF), Fernando Holanda Barbosa (FGV/RJ), Gustavo Franco (PUC/RJ), Joaquim Pinto de Andrade (UnB), Juan H. Moldau (USP), Werner Baer (Univ. de Illinois, E.U.A.).

COMISSĀO EDITORIAL: Atos Freitas Grawunder, Pedro Cezar Dutra Fonseca, Reinaldo Ignacio Adams e Roberto Camps Moraes.

EDITOR: Nali de Jesus de Souza

SECRETARIA: Maria Ivone de Mello (normalização), Vanete Ricacheski (revisão de textos).

FUNDADOR: Prof. Antônio Carlos Santos Rosa

Os materiais publicados na revista Análise Econômica são de exclusiva responsabilidade dos autores. É permitida a reprodução total ou parcial dos trabalhos, desde que seja citada a fonte.

Aceita-se permuta com revistas congêneres. Aceitam-se, também, livros para divulgação, elaboração de resenhas ou recenșões.

Toda correspondência, material para publicação, assinaturas e - permutas devem ser dirigidos ao seguinte destinatário:

\section{PROF. NALI DE JESUS DE SOUZA}

Revista Análise Econômica

Av. João Pessoa, 52

CEP 90040-000 - PORTO ALEGRE (RS), BRASIL

Telefones: (051) 228-1633 - 224-6024 ramais 3440 e 3348

Fax: (051) 225-1067 


\title{
ANÁLISE DA VIABILIDADE ECONÔMICA DA IRRIGAÇÃO DA CULTURA DO MILHO PELO SISTEMA PIVÔ-CENTRAL NO RIO GRANDE DO SUL
}

\author{
Lúcia Maria Schirmer1 \\ Juvir Luiz Mattuella2
}

\section{SINOPSE}

O trabalho teve como objetivo avaliar economicamente um sistema de irrigação pressurizado de pivó-central na produçáo de milho. A anślise foi realizada em uma regiảo do estado do Rio Grande do Sul, partindo-se de dados experimentais e estatísticas de precipitaçōes e produtividades. Para avaliar os ganhos económicos do uso da irrigação, utilizou-se uma função de produção do milho, desenvolvida no setor de hidrologia agrícola do IPH/UFRGS, que simula a produção em função da umidade do solo resultante de precipitaçăo natural. A produçäo, assim obtida, é comparada cum produtividades máximas esperadas com o uso de irrigação de 6,8 e 10 ton/ha. Os resultados obtidos através da relação benefficio/investimento foram maiores que zero para as hipóteses de produç $\tilde{\sigma}=\mathbf{s}$ máximas, superiores a seis ton/ha, demonstrando a eficiência do uso da irrigação, mesmo em caráter suplementar, em regiốes de clima semitropical.

\section{INTTRODUÇĀO}

No Rio Grande do Sul, a cultura do milho apresenta produtividade meaia de $2000 \mathrm{Kg} / \mathrm{ha}$, que pode ser considerada baixa pelo potencial genético das cultivares que vêm sendo normalmente utilizadas nas lavou-

1 Engenheira Agrónoma, Mestranda em Economia Rural (IEPE/UFRGS).

2 Professor Adjunto do Departamento de Ciências Económicas da UFRGS. PhD em Economia Rural.

ANÅLISE ECONÔMICA

ANO 10

№ 17

MARÇO/92 P.12 -139 
ras. Estas cultivares, segundo produtores de sementes certificadas, poderiam chegar a mais de $12000 \mathrm{Kg} / \mathrm{ha}$, em condiçōes normais de clima e manejo adequado.

Diversos fatores podem ser arrolados para explicar a baixa produtividade desta cultura e as constantes frustrações de safras que ocorrem com a mesma. Entre estes fatores destacam-se: a) a sensibilidade do milho ao déficit hídrico; b) a má distribuição das chuvas ao longo do perfodo agrícola; c) práticas agrícolas inadequadas e; d) estado de degradação do solo.

O primeiro aspecto já foi bastante estudado, sendo inclusive, conhecidos os perfodos crfticos, onde o stress hidrico afeta mais intensamente a produtividade do milho (AGUINSKY, 1991). O segundo fator restritivo pode ser devidamente superado pelo uso de irrigação na lavoura. Os demais condicionantes também já têm solução técnica largamente conhecida, faltando apenas a decisão dos produtores em adotá-la. Fica claro, então, que as soluções técnicas para os problemas que impedem a obtenção da produtividade potencial da cultura do milho, não são suficientes para que a questão seja resolvida. A decisão por parte dos produtores de adotar ou não determinada tecnologia envolve outras variáveis além dos aspectos técnicos. Fundamentalmente, o produtor resolve adotar um processo alternativo de produção se o mesmo for economicamente viável. Dentro desta ótica, o presente trabalho objetiva desenvolver a avaliação econômica de um dos aspectos condicionantes na produção de milho, visando oferecer subsídios adicionais aos tomadores de decisões.

A má distribuição das chuves no Estado faz com que a irrigação eventualmente possa assumir um papel importante como fornecedor, em caráter suplementar, dos requerimentos hídricos necessários ao desenvolvimento da cultura do milho. embora as estatísticas mostrem que cs totais de precipitação pluviométria, em média, seriam suf:cientes para a condução desta cultura, sua distribuição errática ao longo do ciclo produtivo pode prejudicar sensivelmente o desempenho da mesma. Este fenômeno tem acontecido com certa freqüência no Estado e tem prejudicado bastante a produção de milho.

A questão que se coloca, então, é se a irregularidade na precipitação e, por extensão, seu efeito sobre a produtividade do milho, justifica a adoção da irrigação, visto que esta teria apenas o caráter de complementar à suplementação hídrica do processo natural. Dentro deste contexto, o presente trabalho se propōe a responder este questionamento mediante a elaboração de um estudo de viabilidade econômica do investimento envolvido no processo de irrigação: 


\section{MATERIAL E MÉTODOS}

\section{1 Área de Abrangência}

Para o desenvolvimento do estudo escolheu-se a região contida no quadrilátero formado pelos munić́pios de Santa Rosa, Júlio de Castilhos, Lajeado e Erechim. Esta Região, denominada de Santo Augusto, foi selecionada por ter uma função de produção estimada onde é relacionada a produção de milho com o suprimento de água durante o ciclo da cultura. Alem disso, ela ocupa o primeiro lugar no Estado com a produção deste cereal, sendo, portanto, bastante representativa para o escopo do trabalho (Anuário Estatístico, 1986).

Para a análise da viabilidade econômica, optou-se apenas pelos sistemas de irrigação sob pressão, pelo fato de sua implantação exigir um volume de investimentos em equipamentos mais levado do que os demais. Especificamente concentrou-se a análise no sistema de irrigação de Pivô-Central.

\subsection{Modelo Conceitual}

A avaliação econômica do uso da irrigação é feita sob a ótica privada, computando-se para tanto apenas os custos e benefícios em nível de produtor rural. Desta forma, busca-se uma resposta para a viabilidade do empreeildimento, sob o pressuposto de que o produtor objetiva, primeiramente, a obtenção do resultado econômico. Desta forma, pressupõe-se que o agricultor investirá no processo de iriigação se o valor presente do fluxo de rendimentos líquidos futuios for, no minimo, igual ao montante do investimenio. Colocado de forma equivalente, o empreendimento é viável desde que a relação benefŕcio/custo seja igual ou maior do que a unidade. Este modelo de decisão simples também pode ser enfocado sob o ângulo do uso alternativo dos recursos. Neste particular, o produtor poderia estabelecer o critério de levar adiante um empreendimento desde que a taxa interna de retorno do mesmo fosse, pelo menos, igual àquela que ele obteria empregando os recursos em outra alternativa.

Os indicadores econômicos de avaliação de investimentos relacionados acima, podem ser expressos da seguinte maneira:

$$
V P D=-K+\sum_{n=1}^{n} R_{n}(l+i)^{-n}
$$

onde 
$\mathrm{VPD}=$ Valor presente descontado

$\mathrm{K}=$ Volume de investimentos do empreendimento

$\mathrm{R}_{\mathrm{n}}=$ Retorno Ifquido verificado no n-Ésimo ano

$\mathrm{i}=$ Taxa pela qual os retornos líquidos são descontados

A relação beneff́cio/custo pode ser apresentada como sendo:

$B / C=V P L / K=I \sum_{n=1}^{n} R_{n}(1+1)^{-n} J / K$

onde:

$\mathrm{B}=$ Benefícios do projeto

$\mathrm{C}=$ Custo do projeto (investimento)

VPL $=$ Valor presente do fluxo de retornos liquidos

A taxa interna de retorno (TIR), como foi referido anteriormente, constitui-se em outio indicador econômico para a análise de projtos. Segundo CENA \& ROMERO (1989), o investimento é tratado como um empréstimo, e a TIR torna-se um indicador da eficiência do investimento para o investidor. Este indicador, segundo MISHAN (1976), mostra a taxa de desconto (i) que torna o valor presente de todo o fluxo de benefrcios liquidos do projeto exatamente igual a zero. Assim, a TIR permite fazer-se comparações da taxa de retorno dos recursos envolvidos no projeto com seus usos alternativos. Esta medida, de forma simplificada, pode ser expressa assim:

$$
\sum_{n=1}^{n} R_{n}(1+T I R)^{-n}=0
$$

\subsection{Operacionalização do Modelco}

Os dados utilizados na elaboração da análise econômica foram reunidós etn três grupos de parâmetos básicos que são:

a) $O$ montante de investimento (K)

b) A vida útil do projeto (n)

c) Retornos líquidos de caixa gerados pelo projeto ao longo de sua vida útil (Rn)

\subsubsection{Montante do Investimento}

Por montante de investimento (K), entende-se o valor do desembolso que o investidor deve realizar para que o projeto possa funcionar. No 
caso especffico do projeto de irrigação, o investimento e formado por três itens principais: equipamentos, rede elétrica e infra-estrutura.

Todo o conjunto de peças, sistemas e canalizaçōes, juntamente com a unidade de captação e bombeamento, compõe o equipamento denominado de Pivô-Central. $O$ custo destes equipamentos foi calculado com base nos preços médios de mercado vigentes em 1988 e transformado em dólares por hectare (US $\$ /$ ha) ao câmbio da ocasião. Para tanto, utilizouse 70 ha como área média para irrigação com Pivô-Central.

Como não se dispunha de nenhum parâmetro para estabelecer a extenção da rede elétrica necessária ao projeto, arbitrou-se a mesma como sendo de dois $\mathrm{Km}$ de rede trifásica de alta tensão e meio $\mathrm{Km}$ de rede trifásica de baixa tensão. $O$ preço da rede elétrica, com todos os componentes, fó̀ obtido junto à Companhia Estadual de Energia Elétrica (CEEE) do Rio Grande do Sul e também foi expresso em dolares por hectare.

A infra-estrutura do projeto é formada pelo conjunto de obras e serviços necessários à condução do mesmo. Ela compreende a casa das bombas, o pé da torre itó pivô, valas de drenagem e preparo da área. $\mathrm{O}$ çusto de todos estes itens formam o investimento necessário em infraestrutura para a operacionalização do projeto. Este custo também foi calculado em dólares por hectare com base no parâmetro de área coberta pelo sistema de irrigação.

A tabela 1 resume os custos de cada item e o total de investimentos necessários para instalar o Pivô-Central.

Tabela 1 - Investimento Para Implantação do Sistema de Irrigação de Pivô-Centra! (em dólares por hectare).

\begin{tabular}{lr}
\hline \multicolumn{1}{c}{ Item } & \multicolumn{1}{c}{ Valor } \\
\hline Equipamentos & $2.158,55$ \\
Rede Elétrica & 229,70 \\
Infra-Estrutura & 157,57 \\
Total & $2.545,82$ \\
\hline
\end{tabular}

Fonte: Cálculo dos autores.

\subsubsection{Vida util do Projeto}

A vida útil do projeto (n) corresponde ao número de ano em que o investimento estará funcionando. Vários são os critérios que podem ser 
adotados para a escolha do elemento que define esta vida útil. Neste trabalho, considerou-se o critério de limitar a vida útil do investimento pelo elemento que representa a maior porcentagem to investimento: o PivôCentral.

O tempo de utilidade de um Pivô-Central é, em media, de 15 anos, ficando assim definido o lapso de tempo da duração do projeto. No final deste perfodo, pressupóe-se que o valor residual dos elementos componentes do mesmo tivessem valor nulo ou não significativo.

\subsubsection{Retornos Llquidos}

Ao longo de sua vida útil um investimento gera um fluxo monetário lfquido $(\mathrm{Rn})$ compreendido pelas entradas menos as sardas. As entradas correspondem aos ingressos anuais atriburdos à venda dos produtos obtidos por meio do investimento. As safdas são formadas pelos desembolsos necessários, a cada ano, para a obtenção dos produtos. A diferença entre as entradas e as safdas constitui o fluxo de caixa ou retorno lfquido $(\mathrm{Rn})$ gerado pelo investimento no n-ésimo ano. Como foi estabelecido que a duração do projeto é de 15 anos, para cada um deles ter-sea um rendimento líquido que, em conjunto, formam o fluxo de benefícios calculados para o mesmo.

As entradas foram obtidas pela multiplicação do preço do milho pela produção atriburda ao projeto. Esta última representa, para cada ano, a quantidade de milho a mais que seria obtida com a irrigação em relação àquela possível de ser obtida sem o processo de irrigação.

Informaçôes do Instituto de Pesquisas Agronômicas (IPAGRO, 1983) dão conta de que no perfodo de um ano, apenas um ciclo da cultura pode ser realizado, e ainda que os fatores climáticos são os responsáveis por esta restrição, e determinam também a melhor época de semeadura ¿a mesma. Sçguindo-se a recomendação para a região em estudo, a data da semeadura do milho deve ocorrer nos primeiros dias de outubro e, conseqüentemente, sua colheita é estimada para o ińrcio do mês de fevereiro, observando-se o ciclo da cultura de 120 dias.

Para calcular o diferencial de produtividade referido acima, tomouse a produtividade obtenfvel com a precipitação ocorrida no perfodo do ciclo da cultura e o limite máximo de produtividade considerado ating1vel com a irrigação. Este último foi fixado em três nfveis: $6000 \mathrm{Kg} / \mathrm{ha}$, $8000 \mathrm{Kg} / \mathrm{ha}$ e $10000 \mathrm{Kg} / \mathrm{ha}$, respectivamente. O limite mais alto foi estabelecido com base nos resultados de pesquisas realizadas por diversos órgãos de pesquisa do Estado (IPAGRO, 1980). Os resultados verificádos nestas pesquisas sugerem que tal produtividade seria atingfvel bastando, para tanto, suprir as necessidades de água exigida pela planta e seguir as práticas agrfcolas recomendadas. Os demais niveis foram arbi- 
trados visando obter-se pontos para a curva de rendimento econômico.

A produtividade atingida, a cada ano, sem a irrigação, foi estimada utilizando-se uma função de produção que relaciona a produtividade do milho com a quantidade de precipitação efetiva ocorrida no perfodo compreendido entre a emergência e a maturação leitosa do grão. A função de produção, apresentada abaixo, foi elaborada pelo Instituto de Pesquisas Hidráulicas da Universidade Federal do Rio Grande do Sul (IPH) e por Fernandes (1991), e é específica para a região em estudo.

$$
Y_{j}=0,259 X_{1}^{0,0923 X_{2} 0,254 X_{3} 0,532 X_{4} 0,255}
$$

onde:

$$
\begin{aligned}
& Y_{j}=\text { Produtividade }(\mathrm{Kg} / \mathrm{ha}), \text { no ano } j(j=1,2,3 \ldots 15) \\
& 0.259=\text { constante } \\
& X_{\mathrm{ij}}=\text { Representa a precipitação efetiva acumulada }(\mathrm{mm}) \text { no perfo- } \\
& \text { do referente ao ano } j(i=1, \ldots 4) .
\end{aligned}
$$

Para cada ano $j$ da série, a precipitação é tomada para quatro perfodos distintos de mesma duração (média em torno de 30 dias), referentes aos estágios fenológicos de sensibilidade da cultura do milho, em termos de rendimento, ao efeito desta variável. Estes estágios são:

$X_{1}=$ Emergência

$X_{2}=$ Desenvolvimento vegetativo

$X_{3}=$ Florescimento/enchimentu de grão

$X_{4}=$ Maturação leitosa

Os valores de precipitação pluviométrica utilizados na função de produção para estimar a produtividade de cada ano foram obtidos de wina série histórica referente aos últimos 21 anos. Com este procedimento, pressupõe-se que esta ninesma série de dados de precipitações se repita no futuro próximo, ensejando assim a possibilidade de se estimar a produção de milho que seria obtida pelos produtores na ausência da irrigação.

O preço utilizado para calcular as entradas é expreso em US $\$ / \mathrm{Kg}$, e representa a média dos preços pagos ao produtor no perfodo de 1973 a 1988, menos um desvio-padrão. Para a elaboração da série de preços, considerou-se apenas-aqueles referentes ao mês de fevereiro, pois ê neste perfodo que ocorre a comercialização do produto. A obrigatoriedade da comercialização imediatamente após a colheita, se justifica, por não ser objetivo deste trabalho, analisar variações no çreço do produto durante o armazenamento, ou estudar melhores perfodos de venda.

A escolha do preço médio menos um desvio-padrão caracteriza a 
adoção de um procedimento pessimista. Este posicionamento se justifica pelo fato de conferir uma margem maior de segurança aos resultados da análise. $\mathrm{O}$ preço assim definido foi de 0,12 dólares por $\mathrm{Kg}$ de produto. Este valor multiplicado pelo ganho de produtividade em cada ano gera o fluxo de entradas.

Contrapondo-se a este fluxo de entradas, tem-se as sardas, representadas pelos custos variáveis de produção. Estes custos, que representam 83,65 dólares por hectare, compreendem os gastos com mão-deobra especializada e semi-especializada, enegia elétrica consumida e manutenção dos equipamentos.

Os valores dos retomos lfquidos anuais, por hextare, estimados para o sistema de irrigação são apresentados na tabela 2.

Tabela 2 - Estimativa dos Retornos Lfquidos A.nuais, em Dolares por Hectare, do Projeto de Irrigação.

\begin{tabular}{rrrr}
\hline & \multicolumn{3}{c}{ Niveis de Produtividade por Hectare } \\
\cline { 2 - 4 } Anos & $6000 \mathrm{~kg}$ & $8000 \mathrm{~kg}$ & $10000 \mathrm{~kg}$ \\
\hline 1 & -51.8935 & 197.9906 & 447.8747 \\
2 & 224.2948 & 74.1790 & 724.0632 \\
3 & 64.7522 & 31.1 .6363 & 564.5205 \\
4 & 162.1169 & 412.0011 & 661.8852 \\
5 & 151.3019 & 401.1861 & 651.0702 \\
6 & 340.5485 & 590.4327 & 840.3169 \\
7 & 477.5909 & 727.4750 & 977.3592 \\
8 & -34.3643 & 215.5198 & 465.4040 \\
9 & 52.0339 & 301.9181 & 551.8023 \\
10 & 326.8386 & 576.7228 & 826.6069 \\
11 & 60.5723 & 310.4565 & 560.3406 \\
12 & 172.7948 & 422.6790 & 672.5632 \\
13 & 365.7108 & 615.5950 & 865.4792 \\
14 & 500.2173 & 750.1015 & 999.9857 \\
15 & 255.5123 & 505.3965 & 755.2807 \\
\hline
\end{tabular}

Fonte: Cálculo dos Autores.

Para homogeneizar a série de retornos acima ao valor presente, utilizou-se uma taxa de desconto de $12 \%$. Esta percentagem representa o 
máximo que seria permitido cobrar de um emprestimo, a trulo de juros reais, segundo os preceitos constitucionais em vigor.

\section{RESULTADOS E DISCUSSÃO}

Os resulados obtidos com os modelos de analise para cada um dos indicadores econômicos são apresentados a seguir.

Tabela 3 - Valor Presente Descontado, em Dolares por Hectare, para Três Nivẹis de Produtividade do Milho Irrigado.

\begin{tabular}{cc}
\hline $\begin{array}{c}\text { Nfvel de Produtividade } \\
\text { (quilogramas p/hectare) }\end{array}$ & $\begin{array}{c}\text { Valor Presente Descontado } \\
\text { (dolares p/hectare) }\end{array}$ \\
\hline 6000 & $-971,00$ \\
8000 & 731,00 \\
10000 & $2.433,00$ \\
\hline
\end{tabular}

Fonte: Cálculos dos Autores.

Observa-se que, para o nfvel de produtividade de $6000 \mathrm{Kg} / \mathrm{ha}$, o valor presente descontado dos retornos líquidos e negativo. Isto significa que o fiuxo de rendimentos do projeto de irrigação, para esta produtividade da cultura do milho, gera um fluxo de ingressos líquidos que $\epsilon$ menor do que o investimento de implantação do projeto, dada a taxa de desconto utilizada. De maneira oposta, os valores positivos estimados para os nfveis de produtividade de 8000 e $10000 \mathrm{Kg} / \mathrm{ha}$, respectivamente, indicam que os ganhos 1'quidos esperados com a implementação do projeto seriam maiores do que o investimento inicial necessário. Desta forma, o resultado positivo do valor presente descontado repre senta uma condição necessária que deve ser satisfeita para que, em prinćpio, o investimento no projeto seja rentável.

Os resultados da razão entre beneff́cios e custos do projeto de irrigação para os diferentes níveis de produtividade do milho são mostrados na tabela 4 . Os valores desta relação $B / C$, ou rendimento relativo, seguem o mesmo comportamento do que foi visto anteriormente para os valores obtidos de VPD. O valor obtido para o nfvel de $6000 \mathrm{Kg} / \mathrm{ha} \epsilon$ 0,62 . Este resulado inviabiliza o projeto, se a produção ficar em 6000 $\mathrm{Kg} / \mathrm{ha}$, pois para cada US\$ investido se obtém apenas US\$ 0,65 de retorno. 
Tabela 4 - Relação Benefício-Custo para Três Níveis de Produtividade do Milho Irrigado.

\begin{tabular}{cc}
$\begin{array}{c}\text { Nivel de Produtividade } \\
\text { (quilogramas p/hectare) }\end{array}$ & Relação Beneffcio/Custo \\
\hline 6000 & 0,62 \\
8000 & 1,29 \\
10000 & 1,95 \\
\hline
\end{tabular}

Fonte: Cálculos dos Autores.

Os outros dois niveis de produtividade viabilizam o projeto, pois a relação B/C E maior do que a unidade. Chama a atenção o valor enconrado para o nivel de produtividade mais alta, onde para cada dólar investido, o produtor receberia 1,95 dólares. Para uma produtividade de $8000 \mathrm{Kg} / \mathrm{ha}$, esta proporção cairia de 1,95 para 1,29 .

Os resultados da relação $B / C$ obtidos para os dois nfveis de produtividade mais altos mostram que o produtor, em média, recuperaria o capital investido, bem antes de esgotar-se a vida útil do Pivó-Central. Para o nivel de produtiviciade mais alta ele levaria cerca de sete anos para se ressarcir do dispêndio inicial; enquanto que necessitaria aproximadamente 12 anos para a produtividade de $8000 \mathrm{Kg} / \mathrm{ha} / \mathrm{ano}$.

$O$ último indicador, TIR, confirma os resultados obtidos pelos outros dois índices, quanto à viabilidade do projeto. As taxas estimadas estão mostradas na tabela abaixo.

Tabela 5 - Taxa Interna de Retorno do Projeto de Irrigação de Milho para Difćrentes Niveis de Produtividade.

\begin{tabular}{cl}
\hline $\begin{array}{c}\text { Nfvel de Produtividade } \\
\text { (Quilogramas p/hectare) }\end{array}$ & $\begin{array}{l}\text { Taxa Interna de Retornc } \\
\text { (em percentagem) }\end{array}$ \\
\hline 6000 & 3,83 \\
8000 & 23,41 \\
10000 & 43,68 \\
\hline
\end{tabular}

Fonte: Cálculos dos Autores.

Para o nfvel mais baixo de produtividade do milho, a taxa interna de retornó estimada para o projeto gira em torno de $3,83 \%$, significando que este seria o percentual máximo de juros que o produtor poderia pagar 
para implementar um programa de irrigação nesta cultura. Nota-se que esta taxa $e$ bastante inferior àquela taxa de juro praticada no mercado para os empréstimos agrícolas, ou para aplicações de baixo risco como a caderneta de poupança. É óbvio que, para esta taxa de retorno, seria mai interessante o produto aplicar seus recursos no mercado financeiro, pois ganharia quase o dobro do que obteria com a implantação do projeto.

Entretanto, para produtividade de 8000 e $10000 \mathrm{Kg} / \mathrm{ha}$, a taxa interna de retorno esperada para o programa de irrigação atinge valores de 23,41 e 43,68 pontos percentuais, respectivamente. Estas seriam, pois, as taxas máximas de juros que o produtor poderia pagar por um emprestimo para implantar um Pivô-Central de irrigação para o cultivo do milho. Nota-se que estas taxas de retorno estão bem acima das taxas de juros reais praticadas no mercado para empréstimos agricolas.

No gráfico a seguir, são plotadas as estimativas do valor presente Íquido obtidas na análise. Constata-se que a curva que une estes valores corta o eixo das ordenadas para um nível de produtividade de 7000 $\mathrm{Kg} / \mathrm{ha}$, significando que este é o rendimento mínimo que torna o projeto viável sob as hipóteses consideradas. Cabe ressaltar, ainda, que os valores encontrados na análise de viabilidade são bastante conservadores face a sistemática que foi adotada para o preço do milho. É possível que sob outro cenário, a irrigação seja factf́l mesmo para uma produtividade de $6000 \mathrm{Kg} / \mathrm{ha}$. Para tanto, basta que o preço do milho se situe em torno da média histórica verificada nas últimas duas décadas.

\section{GRÁFICO 1}

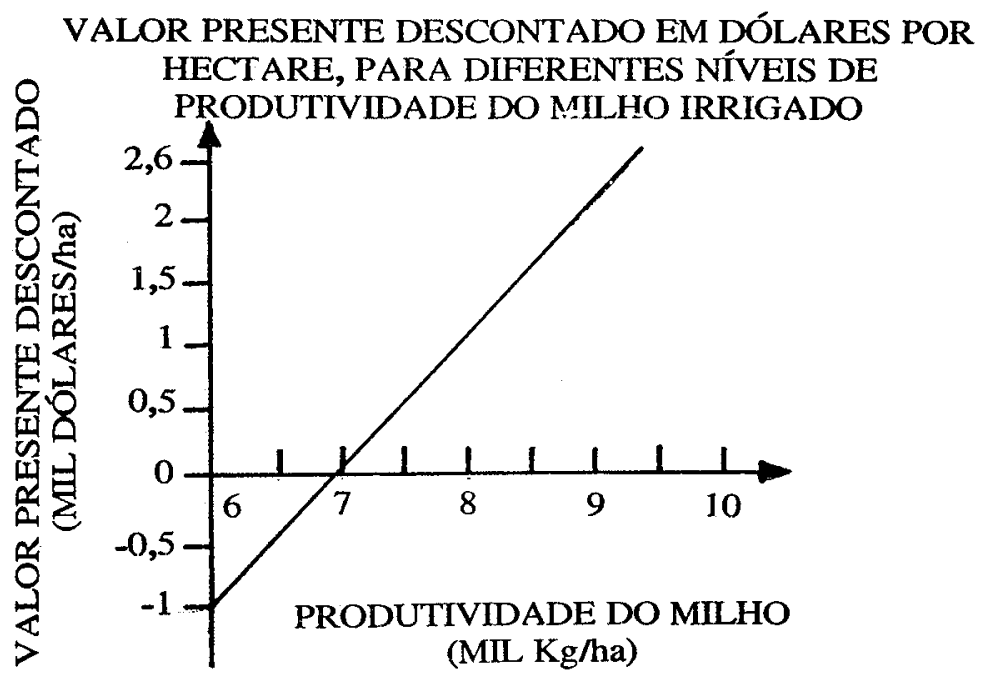




\section{CONCLUSŌES E RECOMENDAÇŌES}

Os resultados obtidos com os três indicadores econômicos pesquisados possibiliam responder a questão fundamental que foi colocada no inf́cio do trabalho: se a irrigação na cultura do milho é ou não viável para os produtores. Face aos resultados da análise, pode-se inferir que, sob as hipoteses estabelcidas, a irrigação pelo sistema de Pivô-Central é economicamente viável a partir de nfveis de produtividades maiores do que $7000 \mathrm{Kg} / \mathrm{ha}$. Salienta-se, entretanto, que esta conclusão é válida, em princípio, para a região delimitada pela área de abrangência do estudo. Porem, não se descarta a hipótese de que a validade dos resultados possa ser estendida para outras regióes, face ao extremo conservadorismo que pautou a elaboração do modelo de análise. Deve se destacar que o limite de produtividade que viabiliza economicamente o projeto situa-se bastante abaixo daqueles observados em experimentos agricolas conduzidos pelos órgãos de pesquisa do Estado. Além disso, tambem deve ser levado em consideração o fato de que as estimativas das receitas foram propositalmente comprimi tas por ter-se adotado como preço para o milho um desvio-padrāo abaixo da média histórica dos últimos 20 anos. Assim, E bastante provável que o processo de irìgação se torne viável mesmo em niveis de produtividade abaixo de $7000 \mathrm{Kg}$ por hectare.

Alternativamente, programas de credito agrifola com taxas de juros baixas tambem poderiam viabilizar projetos de irrigação cujos nf́veis de produtividade se situassem proximos a $6000 \mathrm{Kg} / \mathrm{ha}$.

Em síntese, políticas de preços mínimos adequadas e taxas de juros condizentes com as peculiaridades do setor agricola, poderiam viabilizar projetos de irrigação, mesmo se as produtividades obtidas nos mesmos não fossem tão expressivas. Em contra partida, os benefrcios sociais poderiam ser enormes, pois haveria uma quantidade ofertada do produto relativamente estável e previsf́vel para o abastecimento de mercado interno. Isto traria vantagens tanto aos consumidores finais como para aqueles que usam este cereal à guisa de insumo intermediário. Além disso, o produtor rural teria significativos benefícios pelo fato de ter o risco de produção reduzido e, por decorrência, ampliada a certeza de obter certo nfvel de renda com uma probabilidade bastante alta.

Por firm, recomenda-se que outros estudos emprezando metodologia smelhante sejam desenvolvidos, buscando ampliar o conhecimento a respeito do comportamento dos retornos líquidos, principalmente quando houvesse alterações do preço do produto e dos equipamentos de irrigação, bem como para parametrizaçôes nas taxas de desconto. Além disso, outros métodos de irrigação também deveriam ter sua viabilidade econômica avaliada, principalmente aqueles passíveis de serem empregados em pequenas propriedades rurais. 


\section{BIBLIOGRAFIA}

FERNANDES, Sergio Daniel Aguinsky. Prognóstico e Otimizaçăo do Rendimeato do Milho (Zea mays 1.) no Rio Grande do Sul. Porto Alegre:-Curso de Pós-Graduaçăo em Recursos Hídricos e Saneamento. 1991. 196 f. Dissert. (Mestr. Eng. Civil). UFRGS.

ANUARRIO ESTATISTICO DO RIO GRANDE DO SUL. Estatísticas Gerais, Sociais e Económicas. V1. Porto Alegre: Fundação de Economia e Estatística. 1986. 249p.

CENA, Felisa \& ROMERO, Carlos. Evaluación Económica y Financiera de Inveraiones Agrarias. 2.ed. Madrid, 1989.352p.

IPAGRO, 1983. Ipagro Informa. Porto Alegre. 165p. Fevereiro, n.26.

MISHAN, E.J. 1976. Anf́lise de Custo-Beneffcio. Rio de Janeiro: Zahar, 1976. 487p.

\section{ABSTRACT \\ ECONOMIC ANALYSIS OF PRESSURE IRRIGATION SYSTEM ON MAIZE PRODUCTION IN SOUTHERN BRAZIL}

The subject of study was to perform an economic analysis of pressure irrigation system on maize production, based on a case-study of the central pivo method. The analysis was done for a region of the state of Rio Grande do Sul, using experimental data and informations about precipitation and productivities. To evaluate the economic benefits of using irrigation, a production function of maize developed in the Agricultural Hidrology sector at IPH was used, which simulates production as a function of soil moisture resulting from natural precipitation. The yields of this process was then compared with maximum productivities of 6,8 and 10 ton/ha, expected when using irrigation. The results obtained in the Benefit/Cost ratio were greater than one for the hypothesis of maximum productions higher than 6 ton/ha, demonstrating the effectiveress of irrigation, even wheis utilized as a supplement, in semi-tropical climates. 